\title{
The Role of Supervisor Support, Self-efficacy, and Language Competence in Academic Adaptation of International Graduate Students in Central China
}

\author{
Cherry Kyaw $\operatorname{San}^{1,2} \&$ Hui Guo ${ }^{1}$ \\ ${ }^{1}$ School of Education, Huazhong University of Science and Technology, Wuhan 430074, P.R. China \\ ${ }^{2}$ Department of English, University of Mandalay, Mandalay, Myanmar \\ Correspondence: Cherry Kyaw San, Department of English, University of Mandalay, Mandalay, Myanmar. Tel: \\ 95-978-155-0031. E-mail: cherrysan56@ gmail.com
}

Received: January 27, 2022

Accepted: February 28, 2022 Online Published: March 1, 2022

doi:10.5539/hes.v12n2p1

URL: https://doi.org/10.5539/hes.v12n2p1

\begin{abstract}
This study examined the influence of supervisor support, self-efficacy, and language competence on the academic adaptation of international graduate students. Quantitative data were collected from a sample of 410 international graduate students at five universities in central China. Correlation and multiple regression analyses were conducted and results showed that supervisor support, self-efficacy, English competence were the significant predictors for the academic adaptation of the international students. Contrary to prediction, the host language (Chinese) did not predict their academic adaptation and possible reasons were discussed. These findings contribute to the growing knowledge in the field of international education, supporting main previous studies. The observed predicting roles of the identified factors imply intriguing considerations for higher education institutions in China to provide interventions for international students with the aim of facilitating smooth adaptation to the new academic context.
\end{abstract}

Keywords: academic adaptation, international students, language competence, self-efficacy, supervisor support

\section{Introduction}

One of the main goals of leading higher education institutions across the world is "to prepare culturally competent individuals with the ability to work effectively with people from different backgrounds" (Zhao et al., 2005). Over the past two decades, globally, the number of students pursuing their tertiary level education out of their home countries has seen a dramatic rise from around 2 million in 2000 to more than 6 million in 2019, a more than threefold increase (UNESCO Institute for Statistics, 2021). The increasing presence of international students on campuses of higher education institutions can bring considerable advantages such as cultural diversity, pluralism and adequate opportunities for learning in the multicultural environment (Willer, 1992) but this continuous growth of international student body is demanding systemic observation for their needs and how to help them successfully adapt to the new academic environment.

With the economic upturn, China has been commonly described as a leading nation of outward student mobility rather than as a leading nation of inward student mobility (Barnett et al., 2016; King \& Raghuram, 2013; Wu, 2019). However, China has become the second-largest country in the world for hosting international students, after the USA (European Association for International Education, 2020). Despite the increasing enrollment of the international students, researches undertaken in the academic aspects of international students at Chinese universities is 'lagging far behind' (Wen et al., 2018) and more studies on their academic experience are in need (Khuram et al., 2021).

There remain limited studies examining the international graduate students' academic experience behind the facts and figures of this population in China. In response, this study aimed to fill this research gap in the evidence with international graduate students attending five universities in central China and applying the proposition of Berry's (1997) Cross-culture Adaptation Framework and Schlossberg's Transition Model (1995). The purpose of this paper is to investigate the relationship between the independent variables (supervisor support, self-efficacy, language competence) and academic adaptation of graduate students in Central China and to determine which factors predict their academic adaptation among supervisor support, self-efficacy, language 
competence.

\section{Literature Review}

\subsection{Theoretical Background}

According to Berry (2005), adaptation can be generally defined as "the relatively stable changes that take place in an individual or group in response to external demands" and it is also "multifaceted" (p.709). Based on the prior studies, Yu and Wright (2016) identified four domains of adaptation problems experienced by international students: environmental; socio-cultural; academic; and psychological. Berry (1997) also maintains that language competence and support from the host society such as supervisor support from the host academic community can influence individual international student's academic adaptation process. Schlossberg, et al. (1995) postulates that four potential resources, namely, situation, self, support and strategies are contributing factors the individual's behavioral and learning change. Hence, Berry's (1997) Cross-culture Adaptation Framework and Schlossberg's Transition Model (1995) suggest that international students' academic adaptation can be influenced by supervisor support, self-efficacy, and language competence.

\subsection{Supervisor Support}

Supervisor support can be defined as the support provided to research candidates by supervisors in terms of experience and mentoring skills (De Clercq et al., 2019; Hadi \& Muhammad, 2019). Previous studies have provided some evidences that substantiate the relationship between supervisor support and academic adaptation (e.g., Elliot \& Kobayashi, 2019; Hussain \& Shen, 2019; Khuram et al., 2021; Wisker, 2005; Yu, \& Wright, 2016). Regarding the empirical studies on supervisor support and academic adaptation, Yu and Wright (2016) explored the socio-cultural adaptation, academic adaptation and satisfaction of international research students in Australia, using qualitative approaches. They reported that relationship and communication with supervisors was a core challenge for international graduate students' academic adaptation and success. In addition, more than half of the participants revealed that they obtained inadequate supervisor support to assist them for their academic adaptation. In addition, Elliot and Kobayashi (2019) conducted a qualitative study and highlighted that supervisor support plays an essential role in facilitating international doctoral students' adaptation into the new academic context. Correspondingly, some scholars (Hussain \& Ali, 2019; Hussain \& Shen, 2019) illustrated that supervisor's guidance as part of university support helped students cope with academic barriers, resulting in successful academic adaptation of international students in China.

\subsection{Self-efficacy}

Self-efficacy generally refers to evaluation by individuals about their capability to reach their ultimate goals (Bandura, 1977, 1997, 2012). Self-efficacy is one of the psychological characteristics that contributes to the student adaptation to a new academic context (Anderson et al., 2012). Previous studies pointed out that self-efficacy played a key role in influencing students' potential for academic adaptation (For instance, Abood et al., 2020; Cordeiro \& Lobo, 2016; Thomas et al., 2009; Valenti \& Faraci, 2021; Yang \& Lee, 2017). Thomas, et al. (2009) examined the association among self-efficacy, motivation, and academic adaptation of African American female students studying in the U.S. Findings revealed that self-efficacy significantly and positively predicted academic adaptation. Likewise, Cordeiro and Lobo (2016) found the positive relationship between self-efficacy and academic adaptation. Similar findings were reported by Yang and Lee (2017) who determined the association between the perceived creative learning self-efficacy and career maturity with the mediating role of academic adaptation. The results indicated that self-efficacy was significantly correlated with academic adaptation.

\subsection{Language Competence}

A growing body of literature has illuminated language competence as one of the barriers to international students for smooth adaptation to the host academic culture (Berry, 1997; Robertson et al., 2000; Kim, 2001; Yu \& Wright, 2017). In the current age of globalization, English language competence has been considered as a basic requirement for pursing tertiary education abroad as most of the leading universities worldwide offer English-medium degree programs for international students (Dentakos et al., 2017; Hsu, 2011; Son \& Park, 2014).

Unquestionably, one of the most supporting factors for successful communication with the receiving community is the host language competence (Masgoret, 2006). Many studies have agreed that one's level of host language competence is associated with overall adaptation to the new society (Cheung, 2013; Galloway \& Jenkins, 2005; Masgoret, 2006; Perrucci \& Hu, 1995; Yu, 2016). For example, Cheung (2013) investigated language, socio-cultural, academic and financial adjustments of mainland Chinese students in Hong Kong. The results 
reported that language is the major barrier for them, and they experienced English language difficulties in the academic context and host language (Cantonese) difficulties in the social setting. It is noted that competence in English and the host language is required for smooth adaptation to the new environment.

\subsection{The Current Study}

To the best of our knowledge, the relationship between the independent variables (supervisor support, self-efficacy, language competence) and academic adaptation of graduate students has not been examined in a unique study sample of international graduate students in the context of China. Grounded in the proposition of Berry's (1997) Cross-culture Adaptation Framework and Schlossberg's Transition Model (1995), and based on the prior empirical findings, the present study aims at testing the hypotheses as follows:

Hypothesis 1 (H1): There is a positive relationship between the independent variables (supervisor support, self-efficacy, language competence) and academic adaptation of international graduate students.

Hypothesis 2 (H2): Supervisor support, self-efficacy, language competence significantly predict the academic adaptation of international graduate students.

\section{Method}

\subsection{Participants and Setting}

The sample comprised 410 international graduate students enrolled in five universities in Wuhan, China: Central China Normal University, China University of Geosciences, Wuhan; Huazhong University of Science and Technology, Wuhan University, and Wuhan University of Technology. Sample characteristics were male (52\%) and female (48\%); age range (25 to 41 and above); master's students (30\%) and doctoral students $(70 \%)$. The participants were from the following regions: East and South Asia (69\%); Africa (20\%); Middle East (5\%); Europe (4\%); America (0.5\%) and missing data (1\%). Study fields of these students were Science, Engineering \& Technology (52\%), and Humanities \& Social Sciences (48\%). In addition, $81 \%$ of the participants enrolled in English-medium degree programs and 19\% in Chinese-medium programs. Regarding year of study, $10 \%$ of them are in their first year, $29 \%$ in second year, $36 \%$ in third year and 25\% in fourth year and above.

\subsection{Measures}

\subsubsection{Supervisor Support}

We utilized the 9-item Supervisor Support Scale developed by Hadi and Muhammad (2019) based on the previous researches (e.g., Abdullah \& Evans, 2011; Arabaci \& Ersozlu, 2010; Hadi \& Muhammad, 2017), being reported as a reliable and valid scale. Sample items include: "My supervisor regularly gives feedback on my performance."; and "My supervisor has the skills and necessary subject knowledge to adequately support my research." In the present study, scores from this scale achieved a Cronbach's $\alpha$ of 0.93 .

\subsubsection{Self-efficacy}

We employed the 9-item Self-efficacy Scale developed by Hadi and Muhammad (2019) based on the previous researches (e.g., Abdullah \& Evans, 2011; Arabaci \& Ersozlu, 2010; Hadi \& Muhammad, 2017), being reported as a reliable and valid scale. Sample items include: "I can always manage to solve difficult problems if try hard enough."; and "I am confident that I could deal efficiently with unexpected events." In the present study, scores from this scale achieved a Cronbach's $\alpha$ of 0.74 .

\subsubsection{Language Competence}

Participants evaluated their overall English and the host language (Chinese) level via one self-reported item for each language, ranging from $1=$ 'Very Weak' to $5=$ 'Excellent'.

\subsubsection{Academic Adaptation}

Academic Adaptation Scale ( $\alpha=.82$ in Cemalcilar et al., 2005) and ( $\alpha=0.86$ in Hsu, 2011) involves eight items to measure international students' Academic Adaptation, being reported as a reliable and valid scale. Sample items include: "I have good communication with faculty and with fellow students in my program."; and "I feel that my grades accurately show my academic ability in this program." In the present study, scores from this scale achieved a Cronbach's $\alpha$ of 0.86 .

\subsection{Procedure}

International graduate students who have lived and studied in China for at least one semester were invited to participate in the online survey via international student WeChat groups of five universities in central China. The individual participants provided online written consent. They received an online cover letter, accompanying the 
survey, stating the purpose of the research, and assuring them that their information would be confidential and anonymous utilized only for academic purposes.

\subsection{Data Analysis}

Preliminary analyses for outliers and influential cases, normality, multicollinearity, and homoscedasticity were performed before the main analysis. This assessment brought down the valid response number from 422 to 410 . Descriptive analysis was done for each instrument to investigate the levels of the observed factors. The correlation analysis was performed using Pearson product-moment to examine the relationship between the independent variables and the outcome variable. After that, a multiple regression analysis was computed to assess how well supervisor support, self-efficacy, and language competence predicted the level of academic adaptation of graduate students. Data analyses were conducted by using IBM SPSS (version 26).

\section{Results}

Prior to the main data analysis, the outliers and influential cases were identified and removed from the data using box-and-whisker plots. After that, all the measured variables were checked for skewness. The skewness values for the study variables are less than $+/-1$ so the data can be assumed normally distributed as stated by Morgan and colleagues (2019). Multicollinearity can be a problem if the VIF values of predictor variables are more than 10 (Myers, 1990) but in this study, the VIF scores for all the independent variables were in the acceptable range. Homoscedasticity was examined using bivariate scatter plot matrices before performing the statistical analyses and the assumption was met.

\subsection{Relationship between the Independent Variables and Academic Adaptation}

Table 1. Mean, Standard Deviation, Skewness and Correlation Analysis of Study Variables

\begin{tabular}{lllllllll}
\hline Variable & $\mathrm{M}$ & $\mathrm{SD}$ & Skewness & 1 & 2 & 3 & 4 & 5 \\
\hline 1. Academic Adaptation & 3.79 & .82 & -.44 & - & $.45^{* * *}$ & $.50^{* * *}$ & .03 & $.16^{* * *}$ \\
2. Supervisor Support & 4.00 & .84 & -.65 & & - & $.22^{* * *}$ & -.09 & -.08 \\
3. Self-efficacy & 3.89 & .79 & -.13 & & - & -.03 & $.19^{* * *}$ \\
4. Chinese Competence & 2.77 & .99 & .03 & & & - & $.22^{* * *}$ \\
5. English Competence & 4.10 & .78 & -.62 & & & & - \\
\hline
\end{tabular}

Note. $* * *=.001$.

The correlation analysis was performed using Pearson product-moment to determine the relationship between the independent variables (supervisor support, self-efficacy, language competence) and academic adaptation of international graduate students. Table 1 shows that among the four independent variable, supervisor support, self-efficacy, and English competence were significantly correlated with academic adaptation $(r=.45, r=.50, r$ $=.16$ respectively). However, there was no significant relationship between Chinese competence and academic adaptation. So, these results partially support Hypothesis 1.

\subsection{Factors Predicting Academic Adaptation}

Table 2. Simultaneous Multiple Regression Analysis Summary for Supervisor Support, Self-efficacy, Chinese Competence, and English Competence Predicting Academic Adaptation $(N=410)$

\begin{tabular}{llll}
\hline Variable & $B$ & SEB & $\beta$ \\
\hline Supervisor Support & .29 & .03 & $.38^{* * *}$ \\
Self-efficacy & .48 & .05 & $.40^{* * *}$ \\
Chinese Competence & .23 & .19 & .05 \\
English Competence & .63 & .25 & $.10^{*}$ \\
Constant & 1.63 & 1.92 & \\
\hline
\end{tabular}

Note. $R^{2}=.38 ; F(4,405)=6 \overline{3.53, p<.001}$

$* * *=p<.001, *=p<.05$.

Multiple regression was computed to examine the best linear combination of supervisor support, self-efficacy, Chinese competence, and English competence for predicting academic adaptation. This combination of variables significantly predicted academic adaptation, $F(4,405)=63.53, p<.001$, with all variables significantly contributing to the prediction except Chinese competence. The adjusted $\mathrm{R}$ squared value was .38 . This indicates 
that $38 \%$ of the variance in academic adaptation was explained by the model. This is a large effect as suggested by Cohen (1988). According to Table 2, it is suggested that self-efficacy contributes most to predicting academic adaptation and that receiving high level of support from supervisors and having high level of English competence also contribute to this prediction. As supervisor support, self-efficacy, and English competence were significant predictors for academic adaptation so Hypothesis 2 was partially supported.

\section{Discussion}

The current study investigated the relationship between the independent variables (supervisor support, self-efficacy, language competence) and academic adaptation, and determined the possible predictors for academic adaptation. The findings supported the proposed hypotheses, except for the correlation and predicting effect of Chinese competence on academic adaptation.

In the present study, a strong positive correlation was found between supervisor support and academic adaptation, and additionally, this support factor positively and significantly predicted the academic adaptation. These results are in line with previous studies (Elliot \& Kobayashi, 2019; Hussain \& Shen, 2019; Wisker, 2005; Yu, \& Wright, 2016). Theses researchers observed that good relationship with and support from supervisors were extremely important for international students' adaptation to a new academic culture. Yu and Wright (2016) reported that around half of the participants in their qualitative study received insufficient support from their supervisors and this type of support was given the greatest weight for their successful academic adaptation. Furthermore, the research by Elliot and Kobayashi (2019) strongly endorsed that supervisors' positive outlook of their role in bridging academic cultures can substantially contribute to students' academic adaptation, leading to academic fulfillment and success.

In compliance with our expectation, self-efficacy was found to have a positively strong association with academic adaptation and it was the best predictor for the academic adaptation among the four contributing factors. These findings are aligned with the previous researches (Cordeiro \& Lobo, 2016; Thomas et al., 2009; Valenti \& Faraci, 2021; Yang \& Lee, 2017). Valenti and Faraci (2021) assume that self-efficacy is likely to enormously influence university adjustment including the facet of academic adjustment because students with a high level of self-efficacy incline to feel able to resolve difficulties with low stress level.

With regard to language competence, positive and significance correlation was found between English competence and academic adaptation. In addition, English competence significantly predicted academic adaptation which is in conformity with the prior studies (Berry, 1997; Robertson et al., 2000; Yu \& Wright, 2017). In a similar view, Cheung (2013) concluded that limited English competence creates academic difficulties for international mainland Chinese students at the initial stage of their study in Hong Kong. However, in the present study, most of the participants were in their second year of graduate studies and above, and English competence was found to predict the academic adaptation. Furthermore, Hussain and Shen (2019) who qualitatively explored the academic adaptation of international students reported that these students faced difficulties in academic writing in English in the context of China.

Surprisingly, Chinese competence did not report the statistically significant correlation and prediction on academic adaptation although some scholars have proved that an individual's level of competence in the language of the receiving community is associated with overall adaptation to the new context (Galloway \& Jenkins, 2005; Masgoret, 2006; Yu, 2016). This may be because most of the participants in this study enrolled in the English-medium degree programs at Chinese universities. Therefore, English competence seems to impact their academic adaptation rather than Chinese proficiency. In addition, this study emphasizes the academic aspect of the adaptation and if it investigated the role of the host language in the socio-cultural adaptation, the findings may have been different.

Regarding practical implication, interventions should be developed, specifically targeting international students' sense of their ability to reach their academic goals as the findings revealed that self-efficacy was the best predictor for academic adaptation. In accordance with self-efficacy theory (Bandura \& Adams, 1977), offering opportunities for students to be involved in goal-setting activities via workshops and seminars may assist them to strengthen their self-efficacy beliefs. With the encouragement of setting attainable short-term or proximal goals, their self-efficacy beliefs are likely to be increased and then academic adaptation. Striving for and reaching such achievable goals may help students attain their long-term goal of academic accomplishment, and then the ultimate goal of degree completion. Behavioral modeling and the emotional support from peers and supervisors can help them develop their self-efficacy and succeed academically (Thomas et al., 2009).

As supervisor support was found to largely contribute to students' academic adaptation, Chinese higher education institutions should set their focus on providing supervisor training in student support in terms of mentoring and 
intercultural skills like "understanding alternative rationale for other ideas, intentions and behaviors" (Elliot \& Kobayashi, 2019). In addition, supervisor support is of benefit for graduate students who can obtain some constructive suggestions from supervisors such as how to publish in peer reviewed journals and how to successfully complete their graduate degree (O’Keeffe, 2020). Moreover, Hussain and Ali (2019) reported that international doctoral students expected close interaction between supervisors and supervisees, constructive feedback, careful guidance and team work to be supported by their supervisors.

The next factor that influences the academic adaptation of international students is English language competence. Given this result, offering institutional support programs and services on English language skills may be a way to enhance the English proficiency and ultimately increase the academic adaptation. Furthermore, English support programs for international students in specific fields of study (e.g., engineering, natural science, and social sciences) should be operated apart from general English language support services (Martirosyan, 2019).

\subsection{Limitation and Suggestions for Further Study}

The current study has some shortcomings that need to be addressed in future studies. Firstly, the study data were cross-sectional so longitudinal data would offer intriguing insights into how to improve academic adaptation of international students across time. Secondly, the findings are generated from self-reported data, which may include social desirability of the participants. Thirdly, this study did not consider further factors such as cultural backgrounds, socio-economic status, and academic performance of the participants. Hence, it is recommended that future researches should include these factors to predict academic adaptation of international students.

\section{Conclusion}

The present study reflects a further understanding of academic adaptation among international graduate students studying at Chinese universities, making a contribution to the existing literature on identifying influencing factors for academic adaptation in the field of international education. Taking into account four variables as possible predictors, the findings revealed that supervisor support, self-efficacy and English competence were positively correlated with and predicted academic adaptation. These findings shed light that high level of support from supervisor, individuals' beliefs in their own capabilities to reach targets, and high level of English competence predict how well international students can adapt to a new academic culture.

\section{Conflict of Interest}

The authors declare no potential conflict of interest.

\section{References}

Abood, M. H., Alharbi, B. H., Mhaidat, F., \& Gazo, A. M. (2020). The Relationship between Personality Traits, Academic Self-Efficacy and Academic Adaptation among University Students in Jordan. International Journal of Higher Education, 9(3), 120-128. https://doi.org/10.5430/ijhe.v9n3p120

Anderson, M. L., Goodman, J., \& Schlossberg, N. K. (2012). Counseling adults in transition: Linking Schlossberg's theory with practice in a diverse world. Springer Publishing Company.

Bandura, A. (1977). Social Learning Theory. New York, NY: General Learning Press.

Bandura, A. (1997). Self-Efficacy: The Exercise of Control. New York, NY: W. H. Freeman and Company.

Bandura, A. (2012). Social cognitive theory. In P. M. Van Lange, A. W. Kruglanski, \& E. Higgins (Eds.), Handbook of Theories of Social Psychology (pp. 349-373). Thousand Oaks, CA: Sage Publications Ltd.

Bandura, A., \& Adams, N. E. (1977). Analysis of self-efficacy theory of behavioral change. Cognitive therapy and research, 1(4), 287-310. https://doi.org/10.1007/BF01663995

Barnett, G. A., Lee, M., Jiang, K., \& Park, H. W. (2016). The flow of international students from a macro perspective: a network analysis. Compare: A Journal of Comparative and International Education, 46(4), 533-559. https://doi.org/10.1080/03057925.2015.1015965

Berry, J. W. (1997). Immigration, acculturation, and adaptation. Applied psychology, 46(1), 5-34. https://doi.org/10.1111/j.1464-0597.1997.tb01087.x

Berry, J. W. (2005). Acculturation: Living successfully in two cultures. International journal of intercultural relations, 29(6), 697-712. https://doi.org/10.1016/j.jintrel.2005.07.013

Cheung, A. C. K. (2013). Language, academic, socio-cultural and financial adjustments of mainland Chinese students studying in Hong Kong. International Journal of Educational Management, 27(3), 221-241. https://doi.org/10.1108/09513541311306459 
Cordeiro, S., \& Lobo, C. C. (2016). Self-efficacy and academic adaptation: Contributions to promote psychological adjustment. Human Frontier Science Program Journal, 10(1), 1-10.

De Clercq, M., Devos, C., Azzi, A., Frenay, M., Klein, O., \& Galand, B. (2019). I Need Somebody to Lean on. Swiss Journal of Psychology, 78(3-4), 101-113. https://doi.org/10.1024/1421-0185/a000224

Dentakos, S., Wintre, M., Chavoshi, S., \& Wright, L. (2017). Acculturation motivation in international student adjustment and permanent residency intentions: a mixed-methods approach. Emerging Adulthood, 5(1), 27-41. https://doi.org/10.1177/2167696816643628

Elliot, D. L., \& Kobayashi, S. (2019). How can PhD supervisors play a role in bridging academic cultures? Teaching in Higher Education, 24(8), 911-929. https://doi.org/10.1080/13562517.2018.1517305

European Association for International Education. (2020, January 27). China's 2020 target: reshaping global mobility flows. Retrieved from

https://www.eaie.org/blog/china-2020-target-reshaping-global-mobility-flows.html

Galloway, F. J., \& Jenkins, J. R. (2005). The Adjustment Problems Faced by International Students in the United States: A Comparison of International Students and Administrative Perceptions at Two Private, Religiously Affiliated Universities. NASPA Journal, 42(2), 175-187. https://doi.org/10.2202/1949-6605.5038

Hadi, N. U., \& Muhammad, B. (2019). Factors Influencing Postgraduate Students' Performance: A High Order Top Down Structural Equation Modelling Approach. Educational Sciences: Theory and Practice, 19(2), 58-73. https://doi.org/ 10.12738/estp.2019.2.004

Hsu, C. (2011). Factors influencing international students' academic and sociocultural transition in an increasingly globalized society (Order No. 3455443). Retrieved from https://search.proquest.com/docview/868529304?accountid=11524

Hussain, M., \& Ali, H. (2019). How to Supervise International PhD Students: A Narrative Inquiry Study. International Journal of Higher Education, 8(5), 143-156. https://doi.org/10.5430/ijhe.v8n5p143

Hussain, M., \& Shen, H. (2019). A Study on Academic Adaptation of International Students in China. Higher Education Studies, 9(4), 80-91. https://doi.org/10.5539/hes.v9n4p80

Khuram, W., Wang, Y., Khan, S., \& Khalid, A. (2021). Academic attitude and subjective norms effects on international doctoral students' academic performance self-perceptions: A moderated-mediation analysis of the influences of knowledge-seeking intentions and supervisor support. Journal of Psychology in Africa, 31(2), 145-152. https://doi.org/10.1080/14330237.2021.1903188

Kim, Y. Y. (2001). Mapping the domain of intercultural communication: An overview. Annals of the International Communication Association, 24(1), 139-156. https://doi.org/10.1080/23808985.2001.11678984

King, R., \& Raghuram, P. (2013). International student migration: Mapping the field and new research agendas. Population, Space and Place, 19(2), 127-137. https://doi.org/10.1002/psp.1746

Martirosyan, N. M., Bustamante, R. M., \& Saxon, D. P. (2019). Academic and social support services for international students: Current practices. Journal of International Students, 9(1), 172-191. https://doi.org/10.32674/jis.v9i1.275

Masgoret, A. M. (2006). Examining the role of language attitudes and motivation on the sociocultural adjustment and the job performance of sojourners in Spain. International Journal of Intercultural Relations, 30(3), 311-331. https://doi.org/10.1016/j.ijintrel.2005.08.004

Morgan, G. A., Barrett, K. C., Leech, N. L., \& Gloeckner, G. W. (2019). IBM SPSS for Introductory Statistics: Use and Interpretation: Use and Interpretation. Routledge. https://doi.org/10.4324/9780429287657

Myers, R. (1990). Classical and modern regression with applications (2nd ed.). Boston, MA: Duxbury.

O'Keeffe, P. (2020). PhD by Publication: Innovative approach to social science research, or operationalisation of the doctoral student ... or both? Higher Education Research \& Development, 39(2), 288-301. https://doi.org/10.1080/07294360.2019.1666258

Perrucci, R., \& Hu, H. (1995). Satisfaction with social and educational experiences among international graduate students. Research in Higher education, 36(4), 491-508. https://doi.org/10.1007/BF02207908

Robertson, M., Line, M., Jones, S., \& Thomas, S. (2000). International students, learning environments and perceptions: A case study using the Delphi technique. Higher Education Research \& Development, 19, 
89-102. https://doi.org/10.1080/07294360050020499

Schlossberg, N. K. (2011). The challenge of change: the transition model and its applications. Journal of Employment Counseling, 48(4), 159-162. https://doi.org/10.1002/j.2161-1920.2011.tb01102.x

Son, J. B., \& Park, S. S. (2014). Academic experiences of international PhD students in Australian higher education: From an EAP program to a PhD program. International Journal of Pedagogies and Learning, 9(1), 26-37. https://doi.org/10.1080/18334105.2014.11082017

Thomas, D. M., Love, K. M., Roan-Belle, C., Tyler, K. M., Brown, C. L., \& Garriott, P. O. (2009). Self-efficacy, motivation, and academic adjustment among African American women attending institutions of higher education. The Journal of Negro Education, 159-171.

UNESCO Institute for Statistics. (2021, September). Education: Inbound internationally mobile students by continent of origin. Retrieved from http://data.uis.unesco.org/index.aspx?queryid=3804

Valenti, G. D., \& Faraci, P. (2021). Predicting University Adjustment from Coping-Styles, Self-Esteem, Self-Efficacy, and Personality: Findings from a Survey in a Sample of Italian Students. European Journal of Investigation in Health, Psychology and Education, 11(3), 894-907. https://doi.org/10.3390/ejihpe11030066

Wen, W., Hu, D., \& Hao, J. (2018). International students' experiences in China: Does the planned reverse mobility work? International Journal of Educational Development, 61, 204-212. https://doi.org/10.1016/j.ijedudev.2017.03.004

Willer, P. (1992). Student affairs professionals as international educators: A challenge for the next century. Working with international students and scholars on American campuses, 161-167.

Wisker, G. (2005). The good supervisor: Supervising postgraduate and undergraduate research for doctoral theses and dissertations. Palgrave-Macmillan.

$\mathrm{Wu}, \quad$ H. (2019). China's international student recruitment as 'outward-oriented' higher education internationalisation: an exploratory empirical inquiry. Compare: A Journal of Comparative and International Education, 49(4), 619-634. https://doi.org/10.1080/03057925.2018.1444469

Yang, A., \& Lee, M. S. (2017). Mediating Effect of Academic Adaptation between the Perceived Creative Learning Self-Efficacy and Career Maturity. International Information Institute (Tokyo). Information, 20(9B), 6827-6834.

Yu, B. (2016). Traveling a Thousand Miles: Determinants of Cross-Cultural Adaptation of Asian Students in Australia. In R. King, \& A. Bernardo (Eds.), The Psychology of Asian Learners (pp. 441-457). Springer, Singapore. https://doi.org/10.1007/978-981-287-576-1_27

Yu, B., \& Wright, E. (2016). Socio-cultural adaptation, academic adaptation and satisfaction of international higher degree research students in Australia. Tertiary Education and Management, 22(1), 49-64. https://doi.org/10.1080/13583883.2015.1127405

Yu, B., \& Wright, E. (2017). Academic adaptation amid internationalisation: The challenges for local, mainland Chinese, and international students at Hong Kong's universities. Tertiary Education and Management, 23(4), 347-360. https://doi.org/10.1080/13583883.2017.1356365

Zhao, C. M., Kuh, G. D., \& Carini, R. M. (2005). A comparison of international student and American student engagement in effective educational practices. The Journal of Higher Education, 76(2), 209-231. https://doi.org/10.1353/jhe.2005.0018

\section{Copyrights}

Copyright for this article is retained by the author(s), with first publication rights granted to the journal.

This is an open-access article distributed under the terms and conditions of the Creative Commons Attribution license (http://creativecommons.org/licenses/by/4.0/). 